\title{
Role of ICAM-I and E-selectin gene polymorphisms in pathogenesis of PAOD in Egyptian patients
}

This article was published in the following Dove Press journal:

Vascular Health and Risk Management

23 December 2009

Number of times this article has been viewed

\author{
Olfat Shaker' \\ Amr Zahra ${ }^{2}$ \\ Ahmed Sayed ${ }^{3}$ \\ Ayman Refaat ${ }^{4}$ \\ Zakaria El-Khaiat ${ }^{5}$ \\ Gehan Hegazy ${ }^{5}$ \\ Khaled El-Hindawi ${ }^{3}$ \\ Mohamed Ay-El Deen ${ }^{3}$ \\ 'Department of Medical Biochemistry, \\ ${ }^{3}$ Vascular Surgery, Faculty of Medicine, \\ Cairo University, Cairo, Egypt; \\ ${ }^{2}$ Department of Medical Biochemistry, \\ Faculty of Medicine, Fayoum University, \\ Al Fayyum, Egypt; ${ }^{4}$ Vasular Surgery, \\ Faculty of Medicine, Beni Suef \\ University, Beni-Suef, Egypt; ${ }^{5}$ Medical \\ Biochemistry Department, National \\ Research Center, Cairo, Egypt
}

Background: Intercellular adhesion molecule-1 (ICAM-1) and E-selectin have been shown to predict cardiovascular disease (CVD) such as myocardial infarction, stroke, and peripheral arterial occlusive disease (PAOD).

Methods: Two mutations, S128R in E-selectin and K469E in ICAM-1, were investigated in 156 patients with PAOD and 100 control subjects using polymerase chain reaction-restriction fragment length polymorphism (PCR-RFLP) analysis in an Egyptian population.

Results: The distribution of E-selectin genotypes in patients affected by PAOD was $84.6 \%$ for the AA genotype and $15.4 \%$ for the AC genotype. In the control arm the distribution was $97 \%$ for the AA genotype and 3\% for the AC genotype. There was a statistically significance difference in the distribution of the AC genotype in PAOD patients when compared with the control subjects. Additionally, the distribution of ICAM-1 genotypes in patients affected by PAOD was $30.8 \%$ with the EE, $48 \%$ with the EK, and $21.2 \%$ with the KK genotypes. The distribution of ICAM-1 genotypes in control subjects was 13\% EE, 33\% EK and 54\% KK. The EE genotype was significantly more common in PAOD patients than in the controls.

Conclusion: S128R and K469E polymorphisms were associated with increased risk in PAOD. Early detection of these polymorphic genes helps in early prophylaxis against PAOD.

Keywords: polymorphism, PAOD, E-selectin, ICAM-1, RFLP, genotyping

\section{Introduction}

Patients with peripheral arterial occlusive disease (PAOD) show persistently high morbidity and mortality rates. Treatment entails revascularization (by open surgery or endovascular interventions), amputation and medical treatment that includes the modification of risk factors associated with the disease. Inflammation plays a role in the pathogenesis of atherosclerosis and PAOD. ${ }^{1}$

Various inflammatory mediators such as tumor necrosis factor- $\alpha$ (TNF- $\alpha$ ), interleukin-1 $\beta$ (IL-1 $\beta$ ) and bacterial lipopolysaccharide (LPS), increase the expression of cell adhesion molecules (CAMs) including intercellular adhesion molecule-1 (ICAM-1), vascular cell adhesion molecule-1 (VCAM-1) and E-selectin on endothelial cells. $^{2}$ Thus, upon inflammatory stimulation, the endothelial barrier function is rapidly lost and preformed P-selectin is translocated to the luminal surface of endothelial cells, followed by expression and release of E-selectin, ICAM-1, and VCAM-1 - substances that regulate the attachment and trans-endothelial migration of leukocytes. Both macrophages and endothelial cells produce ICAM-1 in response to inflammatory cytokines. ${ }^{3}$ Circulating markers of systemic inflammation such as C-reactive protein (CRP), IL-6, ICAM-1, and E-selectin have been shown to predict the increased probability of future
Correspondence: Olfat Gamil Shaker 25 Street 105, Maadi, Cairo, Egypt

Tel +20127449192

$\mathrm{Fax}+225323679$

Email olfatshaker@yahoo.com 
cardiovascular disease (CVD), such as myocardial infarction, stroke, and PAOD. ${ }^{4}$

The $\mathrm{S}_{128} \mathrm{R}$ polymorphism of the E-selectin gene is of interest for two reasons: first, it is overrepresented in certain patient groups affected by disease that is characterized by an increased adhesiveness of leukocytes to the endothelium; such as atherosclerosis and myocardial infarction and secondly, it is a functional polymorphism since it modifies ligand affinity. ${ }^{5,6}$ This mutation confers an alteration in selectin ligand-binding specificity which leads to a gain of function under flow conditions, possibly amplifying the number of leukocytes that roll and subsequently adhere to the endothelium. ${ }^{7}$ Furthermore, $\mathrm{S}_{128} \mathrm{R}$ transduced endothelial cells support significantly more rolling and adhesion of neutrophils and mononuclear cells compared to epithelial cells (EC)s transduced with wild-type E-selectin. ${ }^{8}$ Substitution of the E-selectin epidermal growth factor domain residue Ser128 with an arginine residue results in E-selectin proteins that have lost the requirement for alpha1-3-linked fucose and are thus able to bind to sialyllactosamine. These $\mathrm{S}_{128}$ R-transduced ECs also exhibit significantly greater levels of phosphorylation of extracellular signal-regulated kinases 1 and 2 together with p38 mitogen-activated protein kinase. This suggests that an altered endothelial signaling pathway is associated with this polymorphism. ${ }^{9}$

ICAM-1 plays a major role in leukocyte infiltration as well as $\mathrm{T}$ cell activation by $\mathrm{B}$ cells. The human ICAM-1 gene is located on chromosome 19p13.3-p13.2 and contains seven exons. Several single-nucleotide polymorphisms (SNPs) of the human ICAM-1 gene have been reported, and functional analyses regarding the association between each polymorphism and certain diseases have been performed. ${ }^{10}$ Two ICAM-1, coding region, biallelic polymorphisms have been identified: Gly (G) or Arg (R) at codon 241 (exon 4) and Lys $(\mathrm{K})$ or Glu (E) at codon 469 (exon 6). ${ }^{11} \mathrm{E} 469 \mathrm{~K}$ is known to be common in all populations and has been analyzed for its association with several inflammatory diseases. ${ }^{12}$ Our aim was to evaluate the association between gene polymorphism of E-selectin and ICAM and PAOD in an Egyptian population.

\section{Subjects and methods}

This study was conducted on 256 Egyptian subjects. They were divided into two groups: a test group of 156 patients suffering from PAOD (78 males and 78 females) and control group that included, 100 age-matched, healthy subjects (48 males and 52 females). The patients were subdivided into two subgroups: 93 diabetic patients with type II diabetes mellitus (DM) and 63 nondiabetic patients (NDM). Patients with PAOD were diagnosed by the presence of intermittent claudications, rest pain, and/or tissue loss in the absence of distal pulsations. Duplex examination was done for all patients to confirm the site of arterial occlusion and the presence of distal run off. Patients were referred from the vascular surgery departments of a number of centers to the Kasr El-Aini Hospital between April 2007 and December 2008. Healthy individuals, recruited consecutively among physicians and coworkers, represented healthy, normal control subjects. Comprehensive informed consents were obtained from all participants included in the study.

\section{Subject inclusion criteria}

Subjects were Egyptian nationals with PAOD at Fontaine's stage II, III, or IV, detected by a detailed history, thorough physical and clinical examination together with laboratory investigation. Demographic data, a detailed history and thorough clinical examination with special emphasis on vascular complications was undertaken for both study groups. Arterial duplex was performed and the sites of occlusion in every PAOD patient were recorded. Appropriate treatment was then undertaken according to patients' presentation, general condition, and state of distal run off. The choice between revascularization by open surgery or endovascular intervention was determined by the TASC II classification. ${ }^{1}$

Routine biochemical tests were performed for all groups and included: Fasting blood glucose, creatinine, urea, lipid profile, alanine aminotransferase (ALT) and aspartate aminotransferase (AST). Molecular biology techniques for genotyping of E-selectin and ICAM-1 on peripheral blood were also undertaken.

\section{Molecular biology techniques DNA extraction}

DNA was extracted from whole blood using QIA amplification kit (Qiagen Inc, Valencia, CA, USA). The DNA concentration was determined by measuring the OD at $260 \mathrm{~nm}$.

\section{Primer sequences}

The two primers used for genotyping of E-selectin $\left(\mathrm{S}_{128} \mathrm{R}\right)$ were designed using Primer 3 software (Primer 3.cgi,V0.2b, Whitehead Institute/MIT Center for Genome Research, Cambridge, MA, USA) based on the published human CD $62 \mathrm{E}$ genomic DNA sequence flanking the exon 4. Also, two primers were used for detection of ICAM (K469E) allelic polymorphisms are given in Table 1 . 
Table I The sequence of primers

\begin{tabular}{lll}
\hline Primer & Sequences & $\begin{array}{l}\text { Product } \\
\text { size }\end{array}$ \\
\hline $\begin{array}{l}\text { E-selectin } \\
\text { (sense) }\end{array}$ & 5'ATGGCACTCTGTAGGACTGCT3' & $357 \mathrm{bp}$ \\
$\begin{array}{l}\text { E-selectin } \\
\text { (antisense) }\end{array}$ & 5'GTCTCAGCTCACGATCACCAT3' & \\
$\begin{array}{l}\text { ICAM-I } \\
\text { (sense) }\end{array}$ & 5'-GGAACCCATTGCCCGAGC-3' & $223 \mathrm{bP}$ \\
$\begin{array}{l}\text { ICAM-I } \\
\text { (antisense) }\end{array}$ & 5'-GGTGAGGATTGCATTAGGTC-3' & \\
\hline
\end{tabular}

Abbreviation: ICAM-I, intercellular adhesion molecule-I.

\section{Genotyping of E-selectin}

Detection of the $\mathrm{S}_{128}$ R polymorphism was carried out by PCR amplification followed by Pst I restriction enzyme digestion. ${ }^{13}$ After digestion, the fragment length of the $\mathrm{CC}$ genotype was $357 \mathrm{bp}$; the fragment lengths of the AA genotype are 219 and $138 \mathrm{bp}$; the fragment lengths of the AC genotype are 357, 219, and 138 bp (Figure 1a).

\section{Genotyping of ICAM-I}

The K469E polymorphism was amplified using two specific primers. The polymerase chain reaction (PCR) products were identified by enzyme digestion with BstUI which cuts the E469 allele but not K469. ${ }^{14}$ The fragment length of the KK, EE and KE genotypes were 223 bp; 136 and 87 bp; 223, 136, and $87 \mathrm{bp}$, respectively (Figure 1b).

\section{Statistical analysis}

The statistical analysis was undertaken using SPSS software (version 17; SPSS Inc., Chicago, IL, USA). Descriptive statistics in form of mean and standard deviation for parametric data were used, while frequency and percentage were used to describe nonparametric data. ANOVA followed by a post-hoc test (Scheffe) were used for comparison of parametric data among the test groups. For genotype of the E-selectin and ICAM, the differences in their frequency were analyzed by the chi-squared test. An unpaired $t$-test was undertaken for comparison of parametric data between the different genotypes of E-selectin.

\section{Results}

The demographic data of all the studied groups are illustrated in Table 2. With regards to the risk factors of smoking, hypertension, and ischemic heart disease (IHD), there was a statistically significant difference between the control group and the patient groups. There was also a statistically significant difference between the diabetic arm and the nondiabetic arm of the patient group regarding smoking, hypertension and cerebrovascular diseases.

The distribution of the site of the lesion revealed $45 \%$ of the patients had superficial femoral artery occlusion, 24\% had infrapopliteal occlusion, and $12 \%$ had iliac occlusion. Infrapopliteal disease was more prevalent in diabetic patients $(32 \%)$. Table 3 shows a detailed distribution of the site of arterial occlusion.

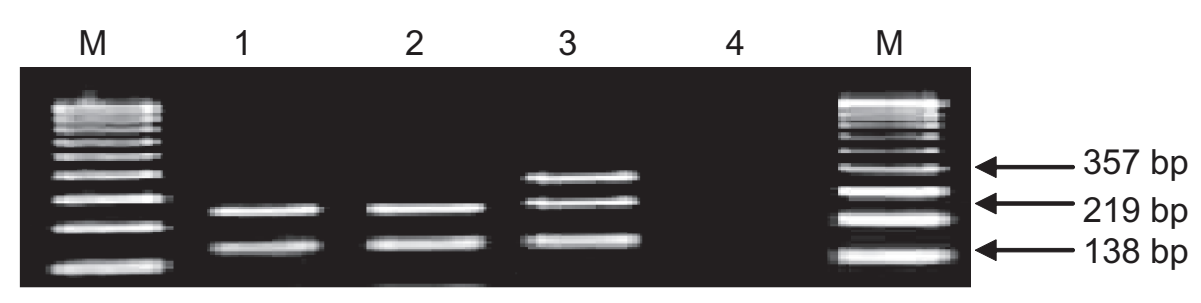

Figure Ia Agarore gel electrophoresis I.5\% stained with ethidium bromide showing the E-selectin DNA product after digestion with Pstl. Lanes M: DNA marker. Lanes I, 2: AA allelic polymorphism. Lane 3: AC allelic polymorphism. Lane 4: negative control.

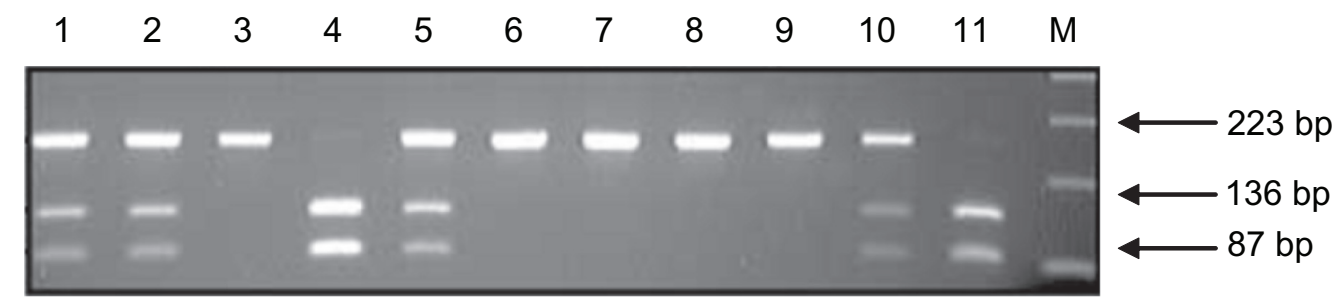

Figure Ib Agarose gel electrophorsis 2.5\% stained with ethidium bromide showing the ICAM-I DNA product after digestion with BstUI. Lanes I, 2, 5, I0: EK allelic polymorphism. Lanes 3, 6-9: KK allelic polymorphism. Lanes 4, I I: EE allelic polymorphism. 
Table 2 The demographic data of all studied groups

\begin{tabular}{|c|c|c|c|c|}
\hline \multirow[t]{2}{*}{ Variables } & \multicolumn{4}{|l|}{ Groups } \\
\hline & Control $(n=100)$ & TPG $(n=156)$ & $D M(n=93)$ & $\operatorname{NDM}(n=63)$ \\
\hline Age (years) & $62.4 \pm 7.6$ & $59.3 \pm 10.7 \mathrm{a}$ & $57.8 \pm 8.9 a$ & $61.6 \pm 12.6 a$ \\
\hline Male & 47 (47\%) & $86(52.1 \%)$ & $53(57 \%)$ & 33 (52.4\%) \\
\hline Female & $53(5.3 \%)$ a & $70(47.9 \%)$ a & $40(43 \%) \mathrm{a}$ & $30(47.6 \%) \mathrm{a}$ \\
\hline \multicolumn{5}{|l|}{ Risk factors } \\
\hline Smokers & 47 (47\%) a & $86(52.1 \%) b$ & $53(57 \%)$ bc & 33 (52.4\%) bd \\
\hline Hypertensive & $20(20 \%) \mathrm{a}$ & $69(44.2 \%) b$ & $57(61.3 \%) b$ & $12(19 . \%)$ a \\
\hline IHD & $0(0 \%) \mathrm{a}$ & $36(23 \%) b$ & 27 (29\%) b & $9(14.3 \%) b$ \\
\hline CVD & $0(0 \%) \mathrm{a}$ & 18 (II.5\%) b & 15 (16.2\%) b & $3(4.8 \%) a b$ \\
\hline \multicolumn{5}{|c|}{ Family history } \\
\hline PAOD & $0(0 \%) \mathrm{a}$ & $3(2 \%) a$ & $0(0 \%) \mathrm{a}$ & $3(4.8 \%) \mathrm{a}$ \\
\hline DM & $6(6 \%) a$ & 60 (38.5\%) b & 17 (54.8\%) b & $9(14.3 \%) \mathrm{a}$ \\
\hline Hypertension & $5(5 \%) \mathrm{a}$ & 27 (I7.4\%) b & 27 (29.\%) b & $3(4.8 \%)$ a \\
\hline
\end{tabular}

Notes: The different letter designations, a-d, indicate significant difference between the variables $(P<0.05)$.

Abbreviations: IHD, ischemic heart disease; CVD, cerebrovascular disease; PAOD, peripheral arterial occlusive disease; TPG, total patient group; DM, diabetes mellitus; NDM, nondiabetes mellitus.

There was no statistically significant $(P>0.05)$ difference between the control group and the patient groups, concerning any family history of the same condition (PAOD). With respect to the family history of both diabetes mellitus and hypertension, there was a statistically significant difference between the control group and NDM patients versus patients with diabetes. However, there was no statistical significance difference between the control group and the NDM patients.

The mean values of the laboratory analyses of blood from both the patients and control groups are given in Table 4.

Genotypes and single allele polymorphism of E-selectin are illustrated in Table 5a. The frequency of AA genotype was higher in the control subjects (97\%) as compared to all in the patient group. The presence of the AA genotype the whole patient group (TPG), the DM patients, and NDM patients was $84.6 \%, 87 \%$, and $81 \%$ respectively. However, there was no statistically significant difference between the control subjects when compared to all patient groups $(P>0.05)$.

The AC genotype occurred in 3\% of the control subjects. However, it was detected in $15.4 \%$ of the TPG, split between the DM patients (13\%) and the NDM patients (19\%). A statistically significant difference $(P<0.05)$ was found between the control subjects and all patient groups; TPG, DM, and NDM. The frequency of the A allele was higher in control group when compared to all the patient groups. The frequency of $\mathrm{C}$ allele was higher in NDM patients $(9.6 \%)$, TPG patients (7.7\%), and DM patients (6.5\%) compared to the control group (1.5\%). There was no statistically significant difference between the different groups regarding allele A although there was between the different groups regarding allele $\mathrm{C}$. There were no statistically significant differences between diabetic group and nondiabetic group regarding the E-selectin genotypes and E-selectin allele.

Distribution of genotype and single allele of ICAM-1 in all groups is given in Table 5b. The frequency of the EE and EK genotypes was significantly lower $(P<0.05)$ in the control subjects than in the TPG, DM, and NDM patients. The frequency of KK genotype was significantly higher in control subjects (53\%) when compared to the patient groups. It was $21.2 \%, 22.6 \%$, and $19 \%$ in the TPG, DM, and NDM patients respectively.

Table 3 Frequency distribution of sites of occlusion for all patients

\begin{tabular}{|c|c|c|c|}
\hline \multirow[t]{2}{*}{ Site of occlusions } & \multicolumn{3}{|l|}{ Frequency } \\
\hline & $\begin{array}{l}\text { TPG } \\
(23 I)\end{array}$ & $\begin{array}{l}\text { DM } \\
\text { (14| sites) }\end{array}$ & $\begin{array}{l}\text { NDM } \\
\text { (90 sites) }\end{array}$ \\
\hline Common iliac artery & $18(7.8 \%)$ & $6(4.3 \%)$ & $4(13.3 \%)$ \\
\hline External iliac artery & $9(3.9 \%)$ & $3(2.1 \%)$ & $2(6.7 \%)$ \\
\hline Popliteal & $42(18.1 \%)$ & $24(17 \%)$ & $6(20 \%)$ \\
\hline SFA & 105 (45.5\%)* & $63(44.7 \%)^{*}$ & $14(46.7 \%)^{*}$ \\
\hline Posterior tibial & 27 (11.7\%) & 21 (14.9\%) & $2(6.7 \%)$ \\
\hline Anterior tibial & $12(5.2 \%)$ & $12(8.5 \%)$ & - \\
\hline Tiboperoneoal & 12 (5.2\%) & $12(8.5 \%)$ & - \\
\hline Dorsalis pedis & $6(2.6 \%)$ & - & $2(6.6 \%)$ \\
\hline
\end{tabular}

Note: $*$ Significant at $(P<0.05)$.

Abbreviations: TPG, total patient group; DM, diabetes mellitus; NDM, nondiabetes mellitus; SFA, superficial femoral artery. 
Table 4 Laboratory data of all studied groups as mean \pm SD

\begin{tabular}{|c|c|c|c|c|}
\hline \multirow[t]{2}{*}{ Variables } & \multicolumn{4}{|l|}{ Groups } \\
\hline & Control $(n=100)$ & TPG $(n=156)$ & $\operatorname{DM}(n=93)$ & $\operatorname{NDM}(n=63)$ \\
\hline FBS (mg/dL) & $91.7 \pm 11.2 \mathrm{a}$ & $176.2 \pm 97.4 c$ & $227.8 \pm 96.3 b$ & $100 \pm 9.7 \mathrm{a}$ \\
\hline Cholesterol (mg/dL) & $170 \pm 16.3 \mathrm{a}$ & $189.8 \pm 55.4 \mathrm{a}$ & $201.7 \pm 61.7 b$ & $172.3 \pm 39.6 \mathrm{a}$ \\
\hline Triglyceride (mg/dL) & $95 \pm 25.4 \mathrm{a}$ & $135.2 \pm 76.6 \mathrm{~b}$ & $142.6 \pm 8 \mid \mathrm{b}$ & $124.2 \pm 70 \mathrm{~b}$ \\
\hline $\mathrm{HDL}(\mathrm{mg} / \mathrm{dL})$ & $62.3 \pm 19.4 \mathrm{a}$ & $39.7 \pm 5.4 \mathrm{~b}$ & $40.3 \pm 59 b$ & $38.8 \pm 45 b$ \\
\hline LDL (mg/dL) & $88.5 \pm 28.3 \mathrm{a}$ & $123.7 \pm 50.5 b$ & $132.8 \pm 56.8 b$ & $110 \pm 36.5 b$ \\
\hline Creatinine (mg/dL) & $\mathrm{I} \pm 0.3 \mathrm{a}$ & $\mathrm{I} \pm 0.3 \mathrm{a}$ & $0.98 \pm 0.3 \mathrm{a}$ & $\mathrm{I} \pm 0.3 \mathrm{a}$ \\
\hline Urea (mg/dL) & $40 \pm 9.7 \mathrm{a}$ & $37.3 \pm 9.2 \mathrm{a}$ & $38.8 \pm 9.8 \mathrm{a}$ & $34.9 \pm 7.9 \mathrm{a}$ \\
\hline AST (IU/L) & $21.2 \pm 6.2 \mathrm{a}$ & $24.8 \pm 9 \mathrm{a}$ & $25.2 \pm 8.9 \mathrm{a}$ & $24.1 \pm 9.5 \mathrm{a}$ \\
\hline ALT (IU/L) & $20.9 \pm 6.2 \mathrm{a}$ & $22.9 \pm 10.3 \mathrm{a}$ & $21.5 \pm 9.2 \mathrm{a}$ & $24.9 \pm 10.8 \mathrm{a}$ \\
\hline $\mathrm{Hb}(g / d L)$ & $12.6 \pm 0.8 \mathrm{a}$ & $12.6 \pm 1.3 \mathrm{a}$ & $12.1 \pm 1.3 \mathrm{a}$ & $12.8 \pm 1.5 \mathrm{a}$ \\
\hline
\end{tabular}

Notes: Different symbols indicate significance. Significant values when $P<0.05$

Abbreviations: TPG, total patient group; DM, diabetes mellitus; NDM, nondiabetes mellitus; FBS, fasting blood sugar; HDL, high-density lipoprotein; LDL, low-density lipoprotein; ALT, alanine aminotransferase; ASDT, aspartate aminotransferase; $\mathrm{Hb}$, hemaglobin; $\mathrm{SD}$, standard deviation.

As regards the frequency of K-allele, it was significantly higher $(P<0.01)$ in control group when compared to all patient groups. While the frequency of the E-allele was significantly lower in control group compared to patient groups. There was no statistically significant difference between the DM and NDM groups regarding both the ICAM-1 genotypes and ICAM-1 alleles.

With respect to the laboratory analyses there were no statistically significant differences between the laboratory data and the different genotypes of ICAM-1 and E-selectin.

The total sites of occlusion for all patients were 231 sites; 141 for 39 of the DM patients, and 90 sites for 24 of the NDM patients. There was no statistical significant difference for sites of occlusion between the DM and NDM patients. The incidence of superficial femoral artery (SFA) occlusion in the TPG, DM, and NDM groups was $45.5 \%, 44.7 \%$, and $46.7 \%$, respectively. The occurrence of
AA and AC polymorphism in patients presenting with SFA were determined as $43.8 \%$ and $53.9 \%$, respectively. There was no statistically significant difference between patients having $\mathrm{AA}$ and $\mathrm{AC}$ genotype regarding the different sites of occlusion. With regard to the ICAM-1 genotypes, the most common site of occlusion was also the SFA. It was concomitant with $40.7 \%, 61.1 \%$, and $40.6 \%$ of the EE, KK, and EK genotypes respectively. There was no statistical significance among different groups of patients regarding other sites of occlusion.

\section{Discussion}

The present study found a statistically significant difference $(P<0.05)$ between the control group and TPG patients regarding the risk factors for atherosclerosis such as smoking and hypertension. Similar results were obtained by both Gaetani and colleagues and Hattori and colleagues. ${ }^{14,15}$ while Schgoer and colleagues and Mueller and colleagues ${ }^{16,17}$ found

Table $\mathbf{5 a}$ Genotypes and alleles of E-selectin among all groups

\begin{tabular}{|c|c|c|c|c|}
\hline \multirow[t]{2}{*}{ Variables } & \multicolumn{4}{|l|}{ Groups } \\
\hline & Control $(n=100)$ & TPG $(n=156)$ & $\mathrm{DM}(\mathrm{n}=93)$ & $\operatorname{NDM}(n=63)$ \\
\hline \multicolumn{5}{|l|}{ E-selectin } \\
\hline AA & 97 (97\%) a & I 32 (84.6\%) a & $8 \mathrm{I}(87 \%) \mathrm{a}$ & $5 \mid(8 \mid \%)$ a \\
\hline$A C$ & $3(3 \%) \mathrm{a}$ & $24(15.4 \%) b$ & $12(13 \%) b$ & $12(19 \%) b$ \\
\hline \multicolumn{5}{|c|}{ Single allele } \\
\hline A & 197 (98.5\%) a & $288(92.3 \%)$ a & $174(93.5 \%) \mathrm{a}$ & I I 4 (90.4\%) a \\
\hline $\mathrm{C}$ & $3(1.5 \%) \mathrm{a}$ & $24(7.7 \%) b$ & $12(6.5 \%) \mathrm{b}$ & $12(9.6 \%) b$ \\
\hline
\end{tabular}

Note: Different symbols indicate statistical significance $(P<0.005)$.

Abbreviations: TPG, total patient group; DM, diabetes mellitus; NDM, nondiabetes mellitus. 
Table 5b Genotype and allele of ICAM in patients and control

\begin{tabular}{|c|c|c|c|c|}
\hline \multirow[t]{2}{*}{ Variables } & \multicolumn{4}{|l|}{ Groups } \\
\hline & $\begin{array}{l}\text { Control } \\
(n=100)\end{array}$ & $\begin{array}{l}\text { TPG } \\
(n=156)\end{array}$ & $\begin{array}{l}\text { DM } \\
(n=93)\end{array}$ & $\begin{array}{l}\text { NDM } \\
(n=63)\end{array}$ \\
\hline \multicolumn{5}{|l|}{ ICAM } \\
\hline $\mathrm{EE}$ & $13(13 \%) \mathrm{a}$ & $48(30.8 \%) b$ & 27 (29\%) b & $2 \mathrm{l}(33.3 \%) \mathrm{b}$ \\
\hline KK & $53(53 \%) a$ & $33(21.2 \%) b$ & $21(22.6 \%) b$ & $12(19 \%) b$ \\
\hline EK & 34 (34\%) a & 75 (48\%) b & 45 (48.4\%) b & 30 (47.7\%) b \\
\hline \multicolumn{5}{|c|}{ Single allele } \\
\hline K & $140(70 \%)$ a & $|4|(45.2 \%) b$ & $87(46.8 \%) b$ & $54(42.8 \%) \mathrm{b}$ \\
\hline$E$ & $60(30 \%) \mathrm{a}$ & I7| (54.8\%) b & 99 (53.2\%) b & $72(57.2 \%) b$ \\
\hline
\end{tabular}

Note: Different symbols indicate significance.

Abbreviations: ICAM, intercellular adhesion molecule; TPG, total patient group; DM, diabetes mellitus; NDM, nondiabetes mellitus.

that coronary artery disease (CAD) was coexistent with PAOD although not present in a control group.

Although the results of this study agree with those of Schgoer and colleagues, ${ }^{16}$ they are at odds with the results of Gaetani and colleagues ${ }^{14}$ as they found no statistically significant difference between the control group and PAOD patients regarding IHD.

In the present work, there were statistically significant differences for a family history of diabetes mellitus or hypertension between the control group versus TPG and DM patients, however, there was no statistical significant difference between controls versus NDM patients. This is in agreement with the case controls study of Pradhan and colleagues. $^{18}$

We also determined there was a statistically significant difference between the control group and diabetic patients regarding cholesterol and for triglycerides between control group and the TPG. These results are in agreement with Iwashima and colleagues, ${ }^{19}$ though they disagreed with those of Mueller and colleagues. ${ }^{18}$ Regarding high-density lipoprotein (HDL) and low-density lipoprotein (LDL) there were significant differences between control versus TPG patients, results that were in agreement with those of both Iwashima and colleagues and Bergmark and colleagues. ${ }^{19,20}$

In the present study it was determined that no statistically significant $(P>0.05)$ difference existed between the control group and the TPG regarding the AA genotype of E-selectin although there was a statistically significant difference regarding AC genotype. These results are in agreement with those reported by Li and colleagues, ${ }^{21}$ who found the distribution of the AA and AC genotypes were $93.8 \%$ and $6.2 \%$ in the control subjects, respectively and $86.7 \%$ and $13.3 \%$ in patients with $\mathrm{CAD}$, respectively. In the study of Yoshida and colleagues, ${ }^{8}$ the frequency of Arg128-positive was significantly higher in patients than in the controls (12.6\% versus $6.7 \%)$. They concluded that the E-selectin Ser128Arg polymorphism can functionally alter leukocyte-endothelial interactions as well as biochemical and biological consequences, which may account for the pathogenesis of myocardial infarction. However, these results contrary to those of Endler and colleagues $^{22}$ who found no significant differences within the genotype distribution of E-selectin $\mathrm{S}_{128} \mathrm{R}$ polymorphism when comparing patients with $\mathrm{CAD}$ to patients without CAD. In this study there was no statistically significant difference among the different groups regarding the A allele although was a significant difference among the different groups regarding $\mathrm{C}$ allele when compared with controls. Similar results were obtained by both Iwashima and colleagues and Meru and colleagues. ${ }^{19,23}$ Moreover, Wenzel and colleagues ${ }^{24}$ reported an allele frequency of the $\mathrm{S}_{128} \mathrm{R}$ polymorphism to be 91.3\% $\mathrm{S}$ and $8.7 \% \mathrm{R}$ in an control population and $84.5 \% \mathrm{~S}$ and $15.5 \% \mathrm{R}$ in patients with severe coronary heart disease (CHD) and that the R128 allele was significantly more common in patients with CHD than in the controls.

Allele distribution was significantly different between our two groups: the E/K-allele ratio was 1.2 in the PAOD group and 0.43 in controls. The frequency of the K-allele was significantly higher for control group than TPG patients, while the frequency of the E-allele was significantly higher for TPG patients than control group. These results are in harmony with other researchers ${ }^{14,25}$ who found the frequency of the EE genotype in patients with PAOD was significantly higher than in controls, while the frequency of the $K K$ genotype was significantly higher in control subjects. The results of Yokoyama and colleagues ${ }^{26}$ found that the distribution of K469E polymorphism in type 2 DM and control subjects was not significantly different between both groups results that are in conflict to our findings although such a difference may be due to differences in the selection of PAOD patients.

In the present work we found no statistical difference between the different polymorphisms and the clinical history and laboratory data among the patient groups except in those with IHD, where there was significant difference between EE and EK (6.2\% vs 3.2\%). These results are in accordance, in part, with those of Milutinovic and Petrovic ${ }^{27}$ who found no statistically significant association between the genotypes and coronary risk factors (clinical history and laboratory).

When comparing the E-selectin and ICAM-1 genotypes with regards to the site of occlusion in the TPG, we found there was no significant association between different groups. We also found that the incidence of SFA, amongst the TPG, 
was the most common form of occlusion, results that are in accordance with Meru and colleagues. ${ }^{23}$

We evaluated the concurrent E-selectin and ICAM-1 genotypes in patients with PAOD with a normal control group and observed no significant association between $\mathrm{AC}$ and $\mathrm{EE}$ genotypes. However, we did find the concurrent association of the AC genotype in the E-selectin gene and EE genotype of ICAM-1 gene in 24 TPG patients. These data support the hypothesis that E-selectin and ICAM-1 are important in the pathophysiology of vascular diseases and suggest a role for anti-inflammatory therapy in the prevention and treatment PAOD.

\section{Disclosures}

The authors report no conflicts of interest in this work.

\section{References}

1. Kumar S, Sharma A, Madan B, Singhal V, Ghosh B. Isoliquiritigenin inhibits IkB kinase activity and ROS generation to block TNF- $\alpha$ induced expression of cell adhesion molecules on human endothelial cells. Biochem Pharmacol. 2007;73:1602-1612.

2. Bartzeliotou AI, Margeli AB, Tsironi M. Circulating levels of adhesion molecules and markers of endothelial activation in acute inflammation induced by prolonged brisk exercise. Clin Biochem. 2007;40:765-770.

3. Tzoulaki I, Murray GD, Lee AJ. C-reactive protein, interleukin-6, and soluble adhesion molecules as predictors of progressive peripheral atherosclerosis in the general population. Circulation. 2005;112: 976-983.

4. Rafiei A, Hajilooi M, Vahedi M, Shakib RJ. The Ser128Arg polymorphism for E-selectin gene and brucellosis. Infect Genet Evol. 2007;10:1016-1030.

5. Alessandro R, Seidita G, Flugy AM. Role of S128R polymorphism of E-selectin in colon metastasis formation. Int J Cancer. 2007;121: 528-535.

6. Rao RM, Clarke JL, Ortlepp S. The S128R polymorphism of E-selectin mediates neuraminidase-resistant tethering of myeloid cells under shear flow. Eur J Immunol. 2002;32:251-260.

7. Yoshida M, Takano Y, Sasaoka T, Izumi T, Kimura A. E-selectin polymorphism associated with myocardial infarction causes enhanced leukocyte endothelial interactions under flow conditions. Arterioscler Thromb Vasc Biol. 2003;23:783-788.

8. Jilma B, Marsik C, Kovar F, Wagner OF, Endler G. The single nucleotide polymorphism Ser128Arg in the E-selectin gene is associated with enhanced coagulation during human endotoxemia. Blood. 2005; 105:2380-2383.

9. Iwao M, Morisaki H, Morisaki T. Single-nucleotide polymorphism (E469K) in human ICAM-1 gene affects mRNA splicing pattern and TPA-induced apoptosis. Biochem Biophys Res Commun. 2004;317: 729-735.
10. Yamashita M, Yoshida S, Kennedy S. Association study of endometriosis and intercellular adhesion molecule-1 (ICAM-1) gene polymorphisms in a Japanese population. J Soc Gynecol Investig. 2005;12(4):267-271.

11. Verity DH, Vaughan RW, Kondeatis E. Intercellular adhesion molecule-1 gene polymorphisms in Behcet's disease. Eur J Immunogenet. 2000; 27:73-76

12. Vallejo R, Fidalgo-Perez I, Malo C, Paredes MM, Kramer J. Spinal neuromodulation: a novel approach in the management of peripheral vascular disease. Tech Reg Anesth Pain Manag. 2006;10:3-6.

13. Shui Qing Ye, Usher D, Virgil D. A Pst 1 polymorphism detects the mutation of Serine 128 to Arginine in CD62E gene - a risk factor for coronary artery disease. J Biomed Sci. 1999;6:18-21.

14. Gaetani E, Flex A, Pola R. The K469E polymorphism of the ICAM-1 gene is a risk factor for peripheral arterial occlusive disease. Blood Coagul Fibrinolysis. 2002;13:483-488.

15. Hattori H, Satoa H, Itoa D. A561C polymorphism of E-selectin is associated with ischemic cerebrovascular disease in the Japanese population without diabetes mellitus and hypercholesterolemia. Brain Res. 2006;1108:21-223.

16. Schgoer W, Mueller T, Jauhiainen M. Low phospholipid transfer protein (PLTP) is a risk factor for peripheral atherosclerosis. Atherosclerosis. 2007;196(1):1-8.

17. Mueller T, Dieplinger B, Poelz W, Haltmayer M. Increased pregnancyassociated plasma protein-A as a marker for peripheral atherosclerosis. Clin Chem. 2006;52:1096-1103.

18. Pradhan AD, Manson JE, Riafai N, Buring JE, Ridker PM. C-reactive protein, interleukin- 6 and risk of developing type 2 diabetes mellitus. JAMA. 2001;286:327-334.

19. Iwashima Y, Horio T, Suzuki Y. Adiponectin and inflammatory markers in peripheral arterial occlusive disease. Atherosclerosis. 2006;188:384-390.

20. Bergmark C, Wu R, de Faire U, Lefvert AK, Swedenborg J. Patients with early-onset peripheral vascular disease have increased levels of autoantibodies against oxidized LDL. Arterioscler Thromb Vasc Biol. 1995; $15: 441-445$

21. Li Y, Wei YS, Wang M. Association between the Ser128Arg variant of the E-selectin and risk of coronary artery disease in the central China. Int J Cardiol. 2005;103:33-36.

22. Endler G, Exner M, Raith M. The E-selectin S128R polymorphism is not a risk factor for coronary artery disease in patients with diabetes mellitus type II. Thromb Res. 2003;112:47-50.

23. Meru AV, Mittra S, Thyagarajan B, Chugh A. Intermittent claudication: An overview. Atherosclerosis. 2006;187:221-237.

24. Wenzel K, Blackburn A, Ernst M. Relationship of polymorphisms in the renin-angiotensin system and in E-selectin of patients with early severe coronary heart disease. J Mol Med. 1997;75:57-61.

25. Pola R, Gaetani E, Flex A. Synergistic effect of $174 \mathrm{~g} / \mathrm{c}$ polymorphism of the interleukin- 6 gene promoter and $469 \mathrm{E} / \mathrm{K}$ polymorphism of the intercellular adhesion molecule-1 gene in italian patients with history of ischemic stroke. Stroke. 2003;34:881-885.

26. Yokoyama H, Tahara H, Emoto M. The K469E polymorphism of the intercellular adhesion molecule-1 gene is associated with plasma fibrinogen level in type II diabetes. Metabolism. 2005;54:381-386.

27. Milutinovic A, Petrovic D. The K469E polymorphism of the intercellular adhesion molecule 1 (ICAM-1) gene is not associated with myocardial infarction in Caucasians with type II diabetes. Folia Biol (Praha). 2006;52:79-80.
Vascular Health and Risk Management

\section{Publish your work in this journal}

Vascular Health and Risk Management is an international, peerreviewed journal of therapeutics and risk management, focusing on concise rapid reporting of clinical studies on the processes involved in the maintenance of vascular health; the monitoring, prevention and treatment of vascular disease and its sequelae; and the involvement of

\section{Dovepress}

metabolic disorders, particularly diabetes. This journal is indexed on PubMed Central and MedLine. The manuscript management system is completely online and includes a very quick and fair peer-review system, which is all easy to use. Visit http://www.dovepress.com/ testimonials.php to read real quotes from published authors. 